\title{
Does Salivary Calcium and Phosphate Concentrations Adequately Reflect Bone Mineral Density in Patients with Chronic Periodontitis?
}

\author{
Somaye Ansari Moghadam ${ }^{1}$, Zahra Zakeri ${ }^{2}$, Sirous Risbaf Fakour ${ }^{1} \&$ Alireza Ansari Moghaddam ${ }^{2}$ \\ ${ }^{1}$ Oral and Dental Disease Research Center, Zahedan University of Medical Sciencesl, Zahedan, IR Iran \\ ${ }^{2}$ Health Promotion Research Center, Zahedan University of Medical Sciences, Zahedan, IR Iran \\ Correspondence: Zahra Zakeri, Health Promotion Research Center, Zahedan University of Medical Sciences, \\ Zahedan, IR Iran. E-mail: zah.zakeri1@gmail.com
}

$\begin{array}{lc}\text { Received: January 23, } 2016 & \text { Accepted: February 24, } 2016 \quad \text { Online Published: March 10, } 2016 \\ \text { doi:10.5539/gjhs.v8n10p282 } & \text { URL: http://dx.doi.org/10.5539/gjhs.v8n10p282 }\end{array}$

\begin{abstract}
Background: Periodontitis is the inflammation of the periodontal supporting tissues. The response of periodontal tissues to local bacteria leads to bone resorption and destruction of periodontal junction. Given the possible association between periodontitis and low bone mineral density, the aim of present study was to find if measurement of salivary biomarkers as a less invasive method, can provide an appropriate screening method for assessment of bone mineral density in patients with chronic periodontitis?
\end{abstract}

Methods: A case-control study was conducted on 53 people, including 28 patients with severe chronic periodontitis and 25 healthy people between April 2014 to March 2015 in Zahedan (southeast of Iran). Following Periodontal examination, salivary samples were collected, and the concentration of salivary calcium and phosphate were measured and reported as $\mathrm{mg} / \mathrm{dl}$. Bone mineral density of participants was measured using dual energy $\mathrm{x}$-ray absorptiometry and reported as $\mathrm{gr} / \mathrm{cm}^{2}$.

Results: No significant association was found between concentrations of salivary calcium and phosphate levels with bone mineral density in either healthy people or in patients with severe chronic periodontitis, despite a significant bone density reduction (in the femur neck and lumbar spine L2-L4) in the periodontitis group compared to healthy people ( $\mathrm{P}=0.006$, and $\mathrm{P}=0.009$ respectively).

Conclusion: Concentration of salivary calcium and phosphate do not appear to be good indicators of bone mineral density. Further prospective studies with larger sample size are recommended.

Keywords: bone density, calcium, chronic periodontitis, dual energy x-ray absorptiometry, phosphate

\section{Introduction}

Osteoporosis (OP) is an asymptomatic disease which is defined as a low bone mass that increased risk of bone fracture. With the invention of Bone densitometry, it is possible to accurately diagnose people at risk of osteoporosis, with prevention and treatment strategies it is possible now to prevent the increased risk of osteoporosis-induced fracture. Dual Energy x-ray Absorptiometry (DEXA) is the method of choice for early detection of osteoporosis and risk of fracture .According to WHO definition, osteoporosis is referred to loss of bone mass $\leq-2.5$ (T.score $<-2.5)$ standard deviations compared to bone mass in healthy young adults, and osteopenia is referred to $-2.5<$ loss of bone $\leq-1$ standard deviation. DEXA calculates bone density using different $\mathrm{X}$-ray absorption rates in soft tissue and bone. DEXA is both accurate (error rate $0.6 \%$ to $1.5 \%$ ) and safe, with little exposure to radiation. DEXA is known as the gold standard in bone density measurement (Leslie, Bernstein, \& Leboff, 2003).

Various studies have reported different prevalence of osteoporosis in patients with periodontitis (Leslie et al., 2014; Tonguc et al., 2014; Wood, Riggs, \& Melton, 1992). Periodontitis is associated with osteoporosis due to release of pro-inflammatory cytokines such as TNF $\alpha$, IL $\beta$, IL6 (Leslie et al., 2003). Thus it seems to be a relationship between systemic bone density and periodontitis (Tonguc et al., 2014).

Screening bone density is recommended for patients with severe chronic periodontitis at risk of osteoporosis, so that further effects of these diseases can be prevented in older patients (Tonguc et al., 2014), and also to prevent extremely high levels of osteoporotic fractures (about 1.5 million fractures per year in America), and 12\%-24\% 
mortality in women and 30\% in men in the first year of fracture, and 50\% inability for self-care (Wood et al., 1992).

Considering high costs and high mortality rates and also osteoporosis-induced disability, it was decided to investigate the mineral bone density in patients with chronic periodontitis and compare the results with healthy people, so that less expensive diagnostic and preventive measures can be taken at the onset of disease following confirmation of bone density loss. An important point in screening for osteoporosis is to find less expensive and available techniques to increase patients' referrals, and subsequently identify high-risk population, and reduce the risk of fracture through appropriate treatments (if necessary). Saliva-based diagnostic tests have become prevalent in recent years because of their less invasive nature, and use of salivary biomarkers is recommended for various cases (Rabiei, Masooleh, Leyli, \& Nikoukar, 2013).

The hypothesis was that salivary calcium and phosphate concentrations can adequately reflect systemic bone conditions. To this end, the present study was designed to investigate the relationship between salivary calcium and phosphate concentrations and variations in bone density in patients with severe chronic periodontitis.

\section{Maerials \& Methods}

In this case-control study, conducted between April 2014 to March 2015 in Zahedan, 60 people were enrolled, of whom 30 had severe chronic periodontitis and 30 were healthy. However, only 53 (28 with periodontitis, and 25 healthy) cooperated until completion of study. This study was approved by Ethical Committee of Zahedan University of Medical Sciences (no.6573). Patients with chronic periodontitis were otherwise systemically healthy and had no disease induced osteoporosis such as rheumatism, malnutrition, Cushing or hyper-parathyroidism and other chronic disease were enrolled. They were all non-smokers and had no history of periodontitis treatments over the last 6 months, and had not used steroidal drugs, or immunosuppressive agents, or anti-osteoporosis drugs, and had at least 8 teeth with $\geq 5 \mathrm{~mm}$ attachment loss. Furthermore, pregnant and breastfeeding women and women with premature menopause were excluded from study. Healthy subjects had normal looking gums, without inflammation, with O'Leary plaque index less than 15\%, and less than 3mm depth of the pockets, requiring no periodontal treatment, and without clinical attachment loss. Next, informed consent forms were signed by all participants. Then, non-stimulated salivary samples were collected from them by spitting, and stored at $-20^{\circ} \mathrm{C}$ until cation measurement. Salivary calcium and phosphate concentrations were measured using spectrophotometry (Kit from Zistchimi Company-Iran). Study subjects were then referred to a credible, ethical, licensed bone densitometry center for screening and assessment of bone density. A single operator blinded to subject's periodontal status determined Bone mineral density (BMD) with Lunar-DpxMD+ (lunar radiation corporation, Madison, WI USA) scanner Dual Energy X-ray Absorptiometry (DEXA), in two areas including lumbar spine, and femoral neck. All patients' details were recorded in data form, which included; BMI, age, gender, medication history, history of chronic diseases, and information about lumbar and femoral mineral bone density. Data collected were analyzed in SPSS-20 using t-test and Pearson's correlation test.

\section{Results}

Table 1. General characteristics of the study groups

\begin{tabular}{lllll}
\hline Characteristic & Periodontal Status & N & Mean \pm Sd & P \\
\hline \multirow{2}{*}{ Age(years old $)$} & Periodontally Healthy & 25 & $51.60 \pm 7.44$ & \multirow{2}{*}{0.13} \\
& Periodontitis Patients & 30 & $48.77 \pm 6.48$ & \\
$\mathrm{Ca}(\mathrm{mg} / \mathrm{dl})$ & Periodontally Healthy & 25 & $3.53 \pm 0.72$ & 0.17 \\
& Periodontitis Patients & 30 & $4.03 \pm 1.82$ & \\
$\mathrm{P}(\mathrm{mg} / \mathrm{dl})$ & Periodontally Healthy & 25 & $10.42 \pm 5.29$ & \multirow{2}{*}{0.10} \\
& Periodontitis Patients & 30 & $13.40 \pm 7.73$ & \\
$\mathrm{BMD} \mathrm{L2-L4}\left(\mathrm{gr} / \mathrm{cm}^{2}\right)$ & Periodontally Healthy & 25 & $1.11 \pm 0.24$ & \multirow{2}{*}{0.009} \\
& Periodontitis Patients & 28 & $0.66 \pm 0.16$ & \\
$\mathrm{BMD} \mathrm{Neck}\left(\mathrm{gr} / \mathrm{cm}^{2}\right)$ & Periodontally Healthy & 25 & $0.99 \pm 0.22$ & \multirow{2}{*}{0.006} \\
& Periodontitis Patients & 28 & $0.83 \pm 0.19$ & \\
$\mathrm{BMD}$ Total Neck $\left(\mathrm{gr} / \mathrm{cm}^{2}\right)$ & Periodontally Healthy & 25 & $1.07 \pm 0.23$ & 0.009 \\
& Periodontitis Patients & 28 & $0.92 \pm 0.15$ & \\
\hline
\end{tabular}


Case group consisted of 28 patients, of whom 14 were female and 14 were male, and control group included 25 healthy people, of whom 13 were female and 12 were male. General characteristics of subjects are presented in Table 1.

According to Table 1, there was no heterogenecity in the mean age of patients with chronic periodontitis (48.77 \pm 6.68$)$ compared to healthy controls $(51.6 \pm 7.66)(\mathrm{P}=0.13)$. Salivary calcium and phosphate concentrations were higher in group of patients with chronic periodontitis compared to healthy group, but the difference was not statistically significant $(\mathrm{P}=0.17$ and $\mathrm{P}=0.1$ respectively). Bone density in lumbar spine $(\mathrm{P}=0.009)$, femoral neck $(\mathrm{P}=0.006)$ and overall bone density $(\mathrm{P}=0.009)$ in patients with chronic periodontitis showed a significant reduction compared to healthy group (Table 2 ).

Table 2. Correlation between salivary minerals and BMD in periodontally healthy subjects

\begin{tabular}{llll}
\hline BMD Salivary mineral & BMD L2-L4 & BMD Neck & BMD Total Neck \\
\hline \multirow{2}{*}{$\mathrm{Ca}$} & $\mathrm{R}=0.3$ & $\mathrm{R}=0.9$ & $\mathrm{R}=0.9$ \\
& $\mathrm{P}=0.2$ & $\mathrm{P}=0.6$ & $\mathrm{P}=0.7$ \\
$\mathrm{p}$ & $\mathrm{R}=0.3$ & $\mathrm{R}=0.03$ & $\mathrm{R}=0.03$ \\
& $\mathrm{P}=0.9$ & $\mathrm{P}=0.9$ & $\mathrm{P}=0.9$ \\
\hline
\end{tabular}

Following Pearson's correlation test, no significant correlation was found between salivary calcium and phosphate concentrations with bone density in healthy group (Table 2), or in patients group (Table 3). In other words, salivary calcium and phosphate concentrations appear not to change in periods of BMD loss.

Table 3. Correlation between salivary minerals and BMD in periodontitis patients

\begin{tabular}{llll}
\hline BMD Salivary mineral & BMD L2-L4 & BMD Neck & BMD Total Neck \\
\hline \multirow{2}{*}{$\mathrm{Ca}$} & $\mathrm{R}=-0.1$ & $\mathrm{R}=0.08$ & $\mathrm{R}=0.02$ \\
& $\mathrm{P}=0.5$ & $\mathrm{P}=0.7$ & $\mathrm{P}=0.09$ \\
$\mathrm{P}$ & $\mathrm{R}=0.06$ & $\mathrm{R}=-0.2$ & $\mathrm{R}=-0.3$ \\
& $\mathrm{P}=0.8$ & $\mathrm{P}=0.3$ & $\mathrm{P}=0.1$ \\
\hline
\end{tabular}

\section{Discussion}

Calcium and phosphorus are among the salivary electrolytes particularly important due to their effective role in bone structure. These two ions are the main constituents of the bone structure and play a significant role in bone regeneration and density. Bone loss, osteoporosis and osteopenia are among the problems that may occur due to reduced absorption of these two electrolytes. Although the systemic bone destruction has been considered as a risk factor for periodontal diseases, the relationship between these two diseases are still unknown (Rabiei et al., 2013).

Bone density screening is a gold standard procedure for screen of osteoporosis, especially because it is less expensive than other methods, and has sufficient sensitivity and specificity. Salivary mineral screening and analysis is less expensive compared to usual bone assessment methods. In Iran, currently, screening for salivary minerals costs 1 Euro, and bone density measurement using densitometry costs about 40 Euros. Cost-effectiveness studies are beneficial, especially in decision-making processes. Advantages of salivary over conventional methods include being less invasive, easily practiced and painless, requiring no personnel training for collection, and costing less. The hypothesis was that salivary calcium and phosphate concentrations change with changes in bone density, and if proven, salivary analysis can be used as a simple, inexpensive technique in bone density screening.

In a study conducted by Tezal on menopausal women, it was observed that the bone density was correlated with the alveolar bone loss in the inter-proximal region and a little correlation was also found between the bone density and the Clinical Attachment Loss (CAL). In other words, menopausal osteopenia was introduced as a risk factor for periodontal diseases in women (Tezal et al., 2000).

Similar to the above study, Lafzi and Von Womern reported that osteoporotic patients had more CAL compared to the control group (Lafzi, Amid, Kadkhodazade, \& Ashrafi, 2013; Womern, Klausen, \& Kollerup, 1994). The 
present study similar to Yoshida, a significant correlation was observed between the periodontal diseases and the low bone density only (Yoshida, Seida, Hanada, \& Miyazaki, 2004). In Yoshida's study, all subjects were over 70 years old, but the mean age of the patients in this studywas $51.60 \pm 7.44$ years. In a study conducted by Kribb, no correlation was observed between the CAL and the bone density both in healthy and osteoporotic people (Kribbs, 1990). Kribb and Klemetti reported that there was an inverse correlation between the bone density and the teeth pocket depth (Kribbs, Cheshunt, Ott, \& Kilocyone, 1989; Klemetti, Fross, Markkanen, \& Lassila, 1994). One of the main problems in bone density-related studies is that the designs of the studies are different which makes them difficult to compare. Furthermore, most studies have been conducted on the elderly, which makes interpreting the results difficult because finding normal bone density and osteopenia in this range of people may be difficult. Ronderos studied the correlation between periodontal diseases and femoral bone density and revealed that the CAL in women with low bone density was more than that in women with normal bone density present (Ronderos, Jacobs, Himes, \& Pihlstrom, 2000). In this study, the people with periodontal diseases had a lower femoral bone density same as the current study. In other words, it seems that the relationship between bone density and periodontal diseases is mutual. However, due to many confounding factors, confirming the relationship between systemic bone density and periodontal diseases is difficult in cross-sectional studies and requires cohort studies. The aim of this study was to evaluate the relationship of salivary calcium and phosphate with bone density as a less-invasive and low cost method. No correlation was observed between the salivary calcium and phosphate and bone density both in healthy subjects and patients with periodontal diseases. Sewon reported that salivary calcium concentration is correlated with bone mineral density in smokers (Sewon et al., 2004), but in the present study, all were non-smokers (which is indicative of strength of study).In other words, it seems that smoking, as a confounding factor, affects the relationship between salivary minerals and bone density and this can justify this contradiction. Further studies in this area, and on the effect of smoking on calcium concentration and bone density are recommended.

Rabiei revealed that salivary calcium concentration can be considered as an appropriate screening tool for women at menopausal age (Rabiei et al., 2004), while such a correlation was not confirmed in our study. This inconsistency may be due to differences in study designs, age and sex of the patients.

The present study showed no significant relationship between changes in bone density and salivary calcium and phosphate concentrations. Although salivary calcium concentration appears to be an important factor in periodontal health, it may be associated with skeletal disorders and loss of bone density in smokers (Sewon et al., 2004).

In a study by Elders, systemic bone density was not an important factor in pathogenesis of periodontitis. However, Elders' study was limited to females in 46 to 55 years age range only (Elders, Habets, Netelenbos, Linden, \& Sieit, 1992), and thus, the majority of participants were perimenopausal, which makes interpretation of results difficult. Conducting cohort studies provides the possibility of more accurate assessment of the relationship between periodontitis and systemic bone density. Payne found that estrogen status in postmenopausal women affected mandibular bone density, and those with adequate estrogen level had appropriate mandibular bone densities, while women with inadequate estrogen levels showed greater loss of mandibular bone density (Payne, Zachs, Reinhardt, Nummikoski, \& Patil, 1997).

In the present study, the mean age of women in both groups was younger than premenopause age and this is another strong point. Patients with periodontitis showed loss of BMD in lumbar spine and femoral neck compared to healthy people. In this study, limitations included small sample size and cross-sectional sampling, and thus, conducting cohort studies with larger sample size is recommended. Moreover, due to lack of similar studies, no comparison was possible. Also, only two of the salivary contents were analyzed, which was another study limitation. Assessment of greater numbers of salivary markers may help identify the right marker associated with bone density. Dentists and other dentistry personnel should recognize risk factors of osteoporosis, and regard periodontitis and other periodontal diseases as an osteoporosis causing disease. Accordingly, the dentist has the duty to inform patients about periodontal treatment, and if needed, refer them for osteoporosis diagnostic tests, for early diagnosis and fracture risk reduction. However, limitations in the present study such as the cross-sectional method and small sample size do not allow to prove a cause and effect relationship.

\section{Conclusion}

Considering the risk of bone density loss in patients with chronic periodontitis, finding the simple method for screening bone density is necessary but requires further studies for early diagnosis and reduction of potential future fractures. 


\section{Acknowledgemens}

This study was supported by Zahedan University of Medical Sciences and Oral and Dental Disease Research Center.

\section{Conflict of Interest}

The authors declare that there is no conflict of interests regarding the publication of this paper.

\section{References}

Cummings, S. R., Black, D. M., Nevitt, M. C., Browner, W., Cauley, J., Ensrud, K., ... Vogt, T. M. (1993). Bone density at variaous sites for prediction of hip fractures. Lancet, 341, 72-75. http://dx.doi.org/10.1016/01406736(93)92555-8

Elders, P. Y., Habets, L. L., Netelenbos, J. C., Vander Linden, L. W., \& Vander stelt, P. F. (1992). The relation between periodontitis and systemic bone mass in women 46 and 55 years of age. J Clin Periodontol, 19, 492-496. http://dx.doi.org/10.1111/j.1600-051X.1992.tb01162.x

Klemetti, E., Collins, H. L., Fross, H., Markkanen, H., \& Lassila, V. (1994). Mineral status of skeleton and advanced periodontal disease. J Clin Periodontol, 21, 184-188. http://dx.doi.org/10.1111/j.1600-051X.1994. tb00301.x

Kribbs, P. J. (1990). Comparison of mandibular bone in normal and osteoporotic women. J Prosthet Dent, 63, 218-222. http://dx.doi.org/10.1016/0022-3913(90)90108-O

Kribbs, P. J., Chesnut, C. H., Ott, S. M., \& Klcoyne, R. F. (1989). Relationship between mandibular and skeletal bone in osteoporotic population. $J$ Prosthet Dent, 62, 703-707. http://dx.doi.org/10.1016/0022-3913 (89)90596-9

Lacativa, P. G., \& Farias, M. L. (2010). Osteoporosis and inframmation. Arq Bras Endocrinolmetabol, 54, 123-132. http://dx.doi.org/10.1590/S0004-27302010000200007

Lafzi, A., Amid, R., Kadkhodazadeh, M., \& Ahrari, F. (2012). Is there any association between systemic bone mineral density and clinical manifestation of periodontal disease. $J$ Periodontol Implant Dent, 4, 49-55.

Leslie, W. D., Bernstein, C. N., \& LeBoff, M. S. (2003). AGA technical review on osteoporosis in hepatic disorders. Gastroenterology, 125, 941-966. http://dx.doi.org/10.1016/S0016-5085(03)01062-X

Payne, J. B., Reinhardt, R. A., Nummikoski, R., \& Patil, K. (2000). The association between estrogen status and alveolar bone loss in post menopausal females. J Clin Periodontol, 27, 658-664. http://dx.doi.org/10.1034/j. 1600-051x.2000.027009658.x

Rabie, M., Massoleh, I. S., Leyli, E. K., \& Nikoukar, L. R. (2013). Salivary calcium concentration as a screening tool for postmenopausal osteoporosis. Int Rhematic Dis, 16, 198-202. http://dx.doi.org/10.1111/1756-185X. 12003

Riggs, B. L., \& Melton, L. J. (1992). The prevention and treatment of osteoporosis. N Engl J Med, 327, 620-627. http://dx.doi.org/10.1056/NEJM199208273270908

Ronderos, M., Jacob, D. R., Himes, J. H., \& Philstrom, B. L. (2000). Association of periodontal disease with femoral bone mineral density and estrogen replacement therapy. Cross-Sectional evaluation of US adults from NHANESш. $J$ Clin Periodontol, 27, 778-786. http://dx.doi.org/10.1034/j.1600-051x.2000. 027010778.x

Sewon, L., Laine, M., Karjalainen, S., Doroguinskaia, A., \& Lehtonen-Veromaa, M. (2004). Salivary calcium refrects skeletal bone density of heavy smokers. Arch Oral Biol, 49, 333-358. http://dx.doi.org/10.1016/j. archoralbio.2003.11.004

Tezal, M., Wactawski-Wende, J., Grossi, S. G., Ho, A. W., Dunford, R., \& Genco, R. J. (2000). The relationship between bone mineral density and periodontitis in postmenopausal women. $J$ Periodontol, 71, 1492-1498. http://dx.doi.org/10.1902/jop.2000.71.9.1492

Toguc, M. O., Buyukkaplan, U. S., Fentoglu, O., Gumus, B. A., Cerci, S. S., \& Kirzioglu, F. Y. (2012). Comparison of bone mineral density in the jaws of patients with and without chronic periodontitis. Dentomaxillofac Radiol, 41, 506-514.

Von Womern, N., Klausen, B., \& Kollerup, G. (1994). Osteoprosis: A risk factor in periodontal disease. $J$ Periodontol, 65, 1134-1138. http://dx.doi.org/10.1902/jop.1994.65.12.1134 
Yoshida, A., Seida, Y., Hanada, N., \& Miyazaki, H. A. (2004). Longitudinal study of the relationship between periodontal disease and bone mineral density in community-dwelling older adults. J Clin Periodontol, 31, 680-684. http://dx.doi.org/10.1111/j.1600-051X.2004.00548.x

\section{Copyrights}

Copyright for this article is retained by the author(s), with first publication rights granted to the journal.

This is an open-access article distributed under the terms and conditions of the Creative Commons Attribution license (http://creativecommons.org/licenses/by/3.0/). 